\title{
Effect of Synthetic Truncated Apolipoprotein C-I Peptide on Plasma Lipoprotein Cholesterol in Nonhuman Primates
}

\author{
Rampratap S. Kushwaha, ${ }^{1 *}$ Henry C. McGill Jr, ${ }^{1}$ and Frederick H. Hausheer ${ }^{2}$ \\ ${ }^{1}$ Department of Physiology and Medicine, Southwest Foundation for Biomedical Research, San Antonio, TX 78245-0549, USA \\ ${ }^{2}$ BioNumerik Pharmaceuticals, Inc, San Antonio, TX 78229, USA
}

Received 24 November 2003; revised 26 May 2004; accepted 2 June 2004

\begin{abstract}
The present studies were conducted to determine whether a synthetic truncated apoC-I peptide that inhibits CETP activity in baboons would raise plasma HDL cholesterol levels in nonhuman primates with low HDL levels. We used 2 cynomolgus monkeys and 3 baboons fed a cholesterol- and fat-enriched diet. In cynomolgus monkeys, we injected synthetic truncated apoC-I inhibitor peptide at a dose of $20 \mathrm{mg} / \mathrm{kg}$ and, in baboons, at doses of 10,15, and $20 \mathrm{mg} / \mathrm{kg}$ at weekly intervals. Blood samples were collected 3 times a week and VLDL + LDL and HDL cholesterol concentrations were measured. In cynomolgus monkeys, administration of the inhibitor peptide caused a rapid decrease in VLDL + LDL cholesterol concentrations (30\%-60\%) and an increase in HDL cholesterol concentrations (10\%-20\%). VLDL + LDL cholesterol concentrations returned to baseline levels in approximately 15 days. In baboons, administration of the synthetic inhibitor peptide caused a decrease in VLDL + LDL cholesterol (20\%-60\%) and an increase in HDL cholesterol (10\%-20\%). VLDL + LDL cholesterol returned to baseline levels by day 21, whereas HDL cholesterol concentrations remained elevated for up to 26 days. ApoA-I concentrations increased, whereas apoE and triglyceride concentrations decreased. Subcutaneous and intravenous administrations of the inhibitor peptide had similar effects on LDL and HDL cholesterol concentrations. There was no change in body weight, food consumption, or plasma IgG levels of any baboon during the study. These studies suggest that the truncated apoC-I peptide can be used to raise HDL in humans.
\end{abstract}

\section{INTRODUCTION}

Plasma high-density lipoproteins (HDL), which are negatively correlated with the extent of coronary atherosclerosis and the risk of coronary heart disease (CHD) $[1,2,3]$, vary considerably among experimental animals and humans $[4,5,6]$. A number of genetic and dietary factors affect plasma HDL cholesterol levels in humans and nonhuman primates $[7,8,9]$. Selective breeding has produced baboons with high and low HDL levels in response to a cholesterol- and fat-enriched diet [5]. The baboons of high-HDL families induce large HDL particles when challenged with a high-cholesterol and high-fat (HCHF) diet [6]. Our metabolic studies suggested that baboons with high HDL have a slower cholesteryl ester transfer from HDL to very low-density lipoproteins (VLDL) and low-density lipoproteins (LDL) on both the low-cholesterol low-fat basal diet and the HCHF diet [6]. The slower cholesteryl ester transfer from HDL to lowerdensity lipoproteins was due to an inhibitor of cholesterol ester transfer protein (CETP) rather than a lack of CETP mass [6]. The CETP inhibitor peptide was identified as an N-terminal fragment of apolipoprotein (apo) C-I [10] with a molecular weight of $4 \mathrm{kd}$. Both the natural and the synthetic CETP inhibitor peptide inhibited CETP activ- ity in the plasma of low-HDL baboons [10]. An antibody against the CETP synthetic peptide increased cholesteryl ester transfer from HDL of high-HDL baboons, whereas the antibody to CETP decreased the cholesteryl ester transfer from HDL of both high- and low-HDL baboons [10]. The present studies were conducted to determine the effect of synthetic truncated apoC-I peptide on plasma VLDL + LDL and HDL cholesterol concentrations in baboons and cynomolgus monkeys consuming the HCHF diet. We also compared the effect of the route of administration of the peptide and the effect of the peptide on body weight, food consumption, and immune response.

\section{MATERIALS AND METHODS}

\section{Animals and diets}

Three adult male baboons $(12-18 \mathrm{~kg})$ and two adult male cynomolgus monkeys $(6-8 \mathrm{~kg})$ were used for these studies. Baboons selected for these studies did not induce large HDL particles in their plasma on the HCHF diet. Both baboons and cynomolgus monkeys consumed the HCHF diet for at least 3 months prior to the start of the experiment and continued consuming the HCHF diet throughout the experimental period. The diet provided 
$40 \%$ of total calories from lard and contained cholesterol at $1.7 \mathrm{mg} / \mathrm{kcal}$ as described previously $[5,6]$. We used another 6 baboons for the measurement of inhibition of cholesteryl ester transfer from HDL to VLDL + LDL in vitro.

\section{Measurement of CETP inhibitor activity of truncated apoC-I peptide}

The effect of truncated apoC-I peptide on mass transfer of cholesteryl ester from HDL to VLDL+LDL was measured by using a whole plasma system [11] or a reconstituted assay system described by us [6]. For assays described here, we used a reconstituted system. Blood (25 mL each) was obtained from a donor and HDL and VLDL+LDL were isolated by ultracentrifugation [6]. HDL was labeled with $\left[{ }^{3} \mathrm{H}\right]$-cholesteryl ester and incubated ( $10 \mu \mathrm{g}$ HDL cholesterol) with 50 to $100 \mu \mathrm{g}$ of VLDL+LDL cholesterol in presence of CETP and $2 \mathrm{mM}$ dithio-bis-dinitrobenzoic acid (DTNB) to inhibit lecithin-cholesterol acyltransferase [6]. CETP was isolated from the plasma of 6 donors as the lipoprotein deficient fraction $d>1.021 \mathrm{~g} / \mathrm{mL}$. Incubations were carried out at $4^{\circ} \mathrm{C}$ and $37^{\circ} \mathrm{C}$ with or without the apoC-I truncated peptide $(25 \mu \mathrm{M})$. The VLDL+LDL was precipitated with 0.1 volume of heparin-manganese chloride to give a final concentration of manganese chloride at $0.092 \mathrm{M}$ and heparin at $1.3 \mathrm{mg} / \mathrm{mL}$ [11]. Radioactivity in HDL fraction was measured by scintillation spectrometry (Beckman Instruments, Palo Alto, Calif). The difference in cholesteryl ester transfer between $4^{\circ} \mathrm{C}$ and $37^{\circ} \mathrm{C}$ was due to CETP activity [6]. The cholesteryl transfer in assay mixture incubated with the truncated peptide was expressed as the percent of transfer in assay mixture incubated without the truncated apoC-I peptide for the same CETP.

\section{Studies in cynomolgus monkeys}

Cynomolgus monkeys were given an intravenous injection of the truncated apoC-I peptide at $20 \mathrm{mg} / \mathrm{kg}$ body weight. Cynomolgus monkeys were implanted with a jugular catheter and maintained on a tether system to facilitate blood drawing and infusion of the synthetic apoC-I peptide. After a steady baseline, the peptide was injected and blood was drawn three times a week.

\section{Studies in baboons}

We studied two modes (subcutaneous and intravenous) of administration of truncated apoC-I peptide in baboons. Baboons were also implanted with a jugular catheter and maintained on a tether system to facilitate blood drawing and infusion of the peptide. Baboons were injected with sterile saline as placebo and cholesterol concentrations of plasma lipoproteins were measured. After a steady baseline, the truncated apoC-I peptide was injected at weekly intervals at 10,15 , and $20 \mathrm{mg} / \mathrm{kg}$ body weight. One dose of radiolabeled (tritium) truncated apoC-I peptide was also injected during each study. Blood samples were drawn three times a week. Food consumption, body weight, and total IgG levels (only one study) were measured.

\section{Synthesis of truncated apoC-I peptide}

The 38 amino acid N-terminal fragment of apoC-I peptide based on human sequences [12] was synthesized at the Microchemical Facility of the Emory University School of Medicine on a contract basis. The baboon peptide has 8 substitutions in this region compared to the human sequence. These substitutions do not change the hydrophobic nature of the peptide. The peptide (both nonradioactive and radioactive) was synthesized by solidphase synthesis using the tBoc/benzyl protection strategy. The peptide was purified by reversed-phase HPLC and was received in freeze-dried form. The purity and structural integrity of the preparation was documented by microbore reversed-phase HPLC and by electrospray ionization tandem mass spectrometry (communication by Dr John Pohl, Director of Microchemical Facility, Emory University, Atlanta, Ga).

\section{Preparation of truncated apoC-I peptide}

For subcutaneous injections, the truncated apoC-I peptide was dissolved in sterile DMSO and then diluted to a concentration of $200 \mathrm{mg} / \mathrm{mL}$ with sterile saline and the final concentration of DMSO was $5 \%$. The solution was frozen and thawed 12 times and stored at $-20^{\circ} \mathrm{C}$ prior to use. A volume of 0.5 to $1.5 \mathrm{~mL}$ was injected subcutaneously. For intravenous injections, the appropriate dose of peptide for each animal was dissolved in $1 \mathrm{~mL} \mathrm{DMSO}$, frozen and thawed 10 times, and diluted with $19 \mathrm{~mL}$ sterile saline. The CETP inhibitor solution was again frozen at $-20^{\circ} \mathrm{C}$ prior to use. A volume of $20 \mathrm{~mL}$ was infused intravenously over 2 hours.

\section{Blood sampling and separation of plasma lipoproteins}

After a fast of approximately 15 hours, blood ( $2 \mathrm{~mL})$ was drawn by a jugular catheter from baboons maintained on a tether system. Blood was centrifuged in a refrigerated low-speed centrifuge (Beckman Instruments, Palo Alto, Calif) to obtain plasma. Lipoproteins were separated by density gradient ultracentrifugation using SW 41 Ti rotor in a Beckman ultracentrifuge Model 8-70 or L8-70M (Beckman Instruments) as described previously in [13]. Fractions were pooled on the basis of their densities measured by refractive index [13]. Densities of pooled fractions corresponded to VLDL + LDL $(d>1.045 \mathrm{~g} / \mathrm{mL})$ and HDL ( $d=1.45$ to $1.21 \mathrm{~g} / \mathrm{mL}$ ). Plasma and lipoprotein cholesterol concentrations were measured every other day for 28 days.

\section{Plasma and lipoprotein cholesterol, triglycerides, and total IgG measurements}

Cholesterol concentrations in plasma and lipoproteins and triglyceride concentrations in plasma were measured by an enzymatic method using a kit from Wako Pure 
Chemical Industries (Richmond). Total plasma IgG was measured by precipitation with saturated ammonium sulfate. The values of $\operatorname{IgG}$ are expressed as microgram per deciliter.

\section{Measurement of plasma apolipoproteins}

Plasma apoA-I and apoE in baboon plasma and apoB in cynomolgus monkey plasma were measured by the electroimmunoassay method as described by Mott et al [14]. The antisera used for these assays were purchased commercially (Boehringer Mannheim, Indianapolis, Ind) and were monospecific.

\section{Measurements of radioactivity in truncated apoC-I peptide in plasma}

A small sample of plasma $(50-100 \mu \mathrm{L})$ was counted in a liquid scintillation counter to measure the radioactivity and was plotted as a percent of radioactivity recovered in plasma at day 2 .

\section{Data analysis}

The data in the figures have been presented as mean \pm SE. The values for lipoprotein cholesterol and apolipoprotein concentrations were compared with the values at day 0 (baseline value) using analysis of variance. The significance was set at $P<.05$. The half-life of the peptide was calculated by plotting data on a log scale. The data were $\log$ linear.

The protocol of this study was approved by the Institutional Animal Care and Use Committee of the Southwest Foundation for Biomedical Research, which is accredited by the American Association for Accreditation of Laboratory Animal Care and is registered with the US Department of Agriculture.

\section{RESULTS}

\section{Effect of truncated peptide on cholesteryl ester transfer from HDL to VLDL + LDL in baboon plasma}

We measured the mass transfer of cholesteryl ester from HDL to VLDL + LDL in vitro in presence or absence (control) of truncated apoC-I peptide. As presented in Figure 1, the addition of truncated apoC-I peptide in the plasma considerably decreased $(21 \%$ to $53 \%$ of control) cholesteryl ester transfer from HDL to VLDL + LDL.

\section{Effect of truncated apoC-I peptide on plasma lipoproteins in cynomolgus monkeys}

Plasma VLDL + LDL cholesterol concentrations for two cynomolgus monkeys used for these studies were 569 and $671 \mathrm{mg} / \mathrm{dL}$. The hypercholesterolemia was mainly due to the increased cholesterol in VLDL + LDL (greater than $90 \%$ of total plasma cholesterol). Plasma HDL cholesterol concentration (64 and $61 \mathrm{mg} / \mathrm{dL}$ for two monkeys) was very low (less than $10 \%$ of total plasma cholesterol). After injection of the truncated apoC-I peptide in cynomolgus monkeys, there was a rapid drop

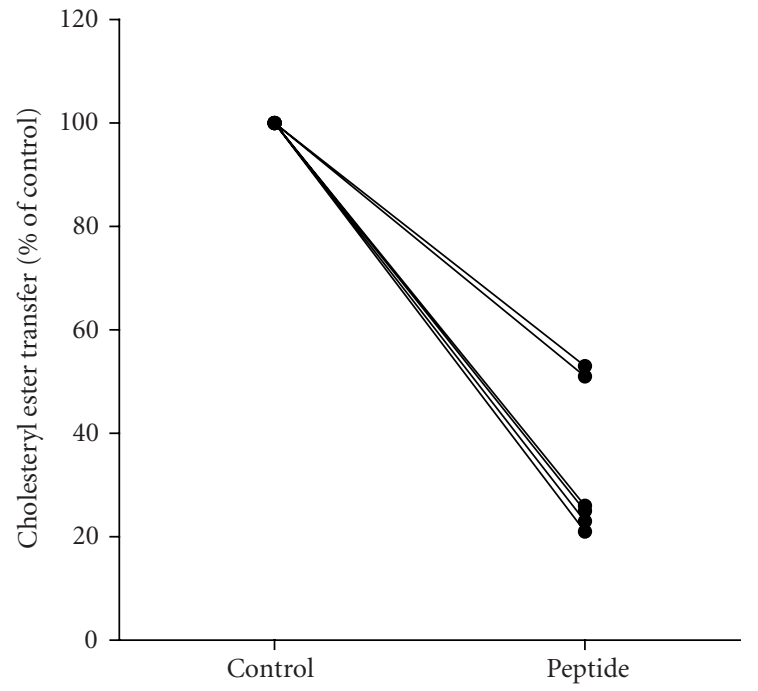

FIgURE 1. Effect of truncated apoC-I peptide on the mass transfer of cholesteryl ester from HDL to VLDL + LDL in reconstitute assays $(n=6)$. The cholesteryl ester transfer in the plasma was measured by adding the truncated apoC-I peptide at a concentration of $25 \mu \mathrm{M}$, as described in "methods." The decrease in cholesteryl ester transfer in plasma added with the truncated peptide (peptide) has been expressed as the percent of transfer in the plasma without the truncated peptide (control).

in the plasma VLDL + LDL cholesterol concentration (Figure 2). The maximum decrease in plasma and VLDL + LDL cholesterol occurred at day 7 in both animals and, at this point, there was a $26.5 \pm 4.5 \%$ decrease in plasma LDL cholesterol levels $(P<.05)$. The values for VLDL + LDL cholesterol levels were also significantly lower $(P<.05)$ on days $3,7,11$, and 14 than the baseline (day 0) VLDL + LDL cholesterol levels. After day 7, the VLDL + LDL cholesterol started to go up and, at day 21, the levels returned to baseline values. The HDL cholesterol concentrations increased at day $4(10 \%-20 \%)$ and remained elevated until day 7 , after which there was a slight drop. There was considerable variability in HDL cholesterol concentrations in both cynomolgus monkeys and therefore, these values were not significantly different from the baseline values (day 0 values).

Baseline values for plasma apoB in two cynomolgus monkeys were 300 and $254 \mathrm{mg} / \mathrm{dL}$. After the injection of the truncated apoC-I peptide, apoB decreased rapidly as did VLDL + LDL cholesterol; the maximum decrease occurred on day 7 (Figure 3). After day 7, the apoB began to increase; like VLDL + LDL cholesterol, the plasma apoB concentration returned to baseline levels by day 21 . The apoB concentrations were lower on days 7, 9, and 11 than the baseline apoB concentrations.

\section{Effect of subcutaneous injections of truncated apoC-I peptide on plasma lipoproteins in baboons}

Compared with cynomolgus monkeys, baboons had moderate hyperlipidemia (VLDL + LDL cholesterol, $148.33 \pm 36.55$; HDL cholesterol, $104.67 \pm 7.33$; and plasma 


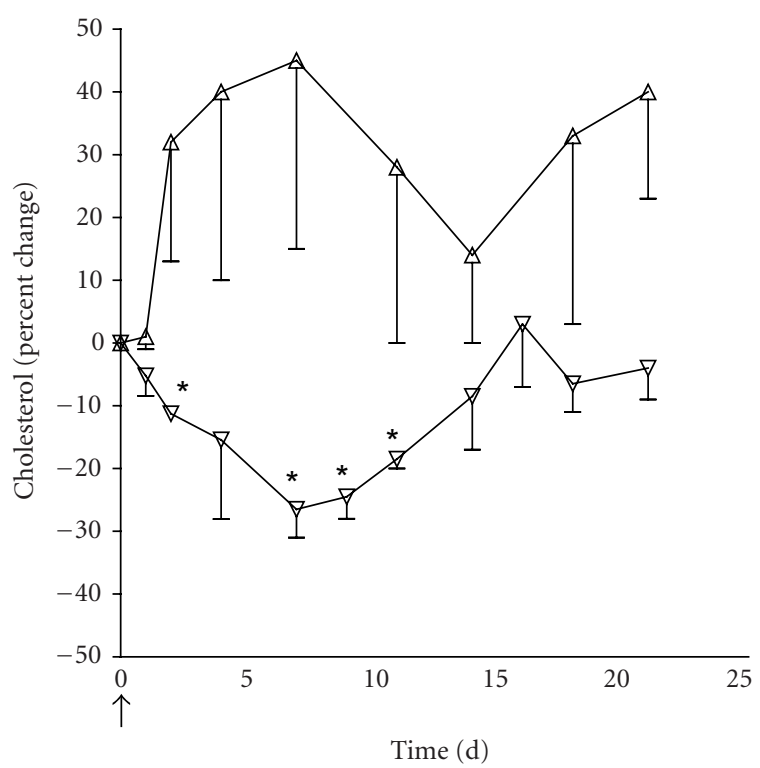

Figure 2. Average percent change in plasma HDL $(\Delta)$ and VLDL + LDL $(\nabla)$ cholesterol concentrations in cynomolgus monkeys after a single injection of the truncated apoC-I peptide at $20 \mathrm{mg} / \mathrm{kg}$ on day 0 (arrow). Monkeys were fed the HCHF diet. Values are expressed as mean \pm SE, $n=2$. Values significantly different from those at day 0 are marked by an asterisk $(P<.05)$.

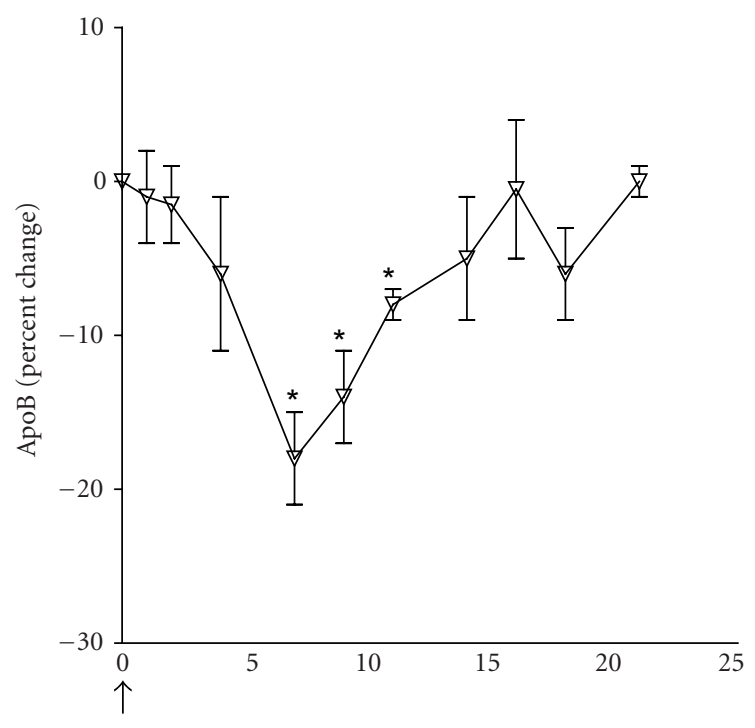

Time (d)

Figure 3. Average percent changes in plasma apoB concentrations in cynomolgus monkeys $(\nabla)$ after a single injection of the truncated apoC-I peptide at $20 \mathrm{mg} / \mathrm{kg}$ on day 0 (arrow). Monkeys were fed the HCHF diet. Values are expressed as mean \pm SE, $n=2$. Values significantly different from those at day 0 are marked by an asterisk $(P<.05)$.

triglycerides, $45.33 \pm 3.48 ; \mathrm{mg} / \mathrm{dL}$, mean $\pm \mathrm{SE})$. Figure 4 presents average percent changes in plasma lipoprotein cholesterol concentrations in 3 baboons injected with CETP inhibitor peptide subcutaneously. After the first

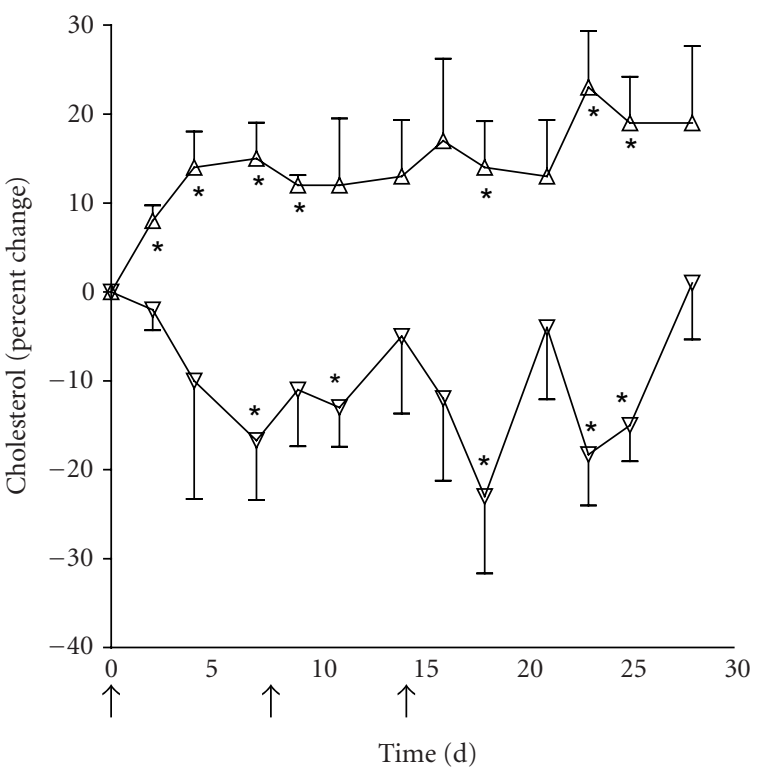

Figure 4. Average percent change in $\operatorname{HDL}(\Delta)$ and VLDL + LDL $(\nabla)$ cholesterol concentrations in baboons after subcutaneous injections of the truncated apoC-I peptide at 10, 15 , and $20 \mathrm{mg} / \mathrm{kg}$ on days 0,7 , and 14, respectively (arrows). The baboons were fed the HCHF diet. Values are expressed as mean \pm SE, $n=3$. Values significantly different from those at day 0 are marked by an asterisk $(P<.05)$.

injection of truncated apoC-I peptide $(10 \mathrm{mg} / \mathrm{kg})$, the HDL cholesterol concentration started to go up, whereas the VLDL + LDL cholesterol concentration started to go down. After the second injection $(15 \mathrm{mg} / \mathrm{kg})$ on day 7 , the HDL and VLDL + LDL cholesterol concentrations remained the same. However, after the third injection $(20 \mathrm{mg} / \mathrm{kg})$ on day 14 , the VLDL + LDL cholesterol went down further but, after day 21, it started to rise and returned to baseline values on day 28. On the other hand, after the third injection, the HDL cholesterol went up and stayed up during the rest of the experimental period. The maximum decrease in VLDL + LDL cholesterol was 20\% on day 19, whereas the maximum increase in HDL cholesterol was $20 \%$ on day 23 . Most of the values of plasma LDL and HDL cholesterol concentrations after the treatment with truncated apoC-I peptide were significantly different from values at the baseline.

\section{Effect of intravenous injections of truncated apoC-I peptide on plasma lipoproteins in baboons}

Figure 5 presents the average changes in plasma lipoprotein cholesterol in 3 baboons injected with truncated apoC-I peptide intravenously. As in the case of subcutaneous injections, after the first injection $(10 \mathrm{mg} / \mathrm{kg})$, there was a rapid increase in HDL cholesterol and a rapid decrease in VLDL + LDL cholesterol. After the second injection $(15 \mathrm{mg} / \mathrm{kg})$, there was no further change in HDL cholesterol concentration; however, there was a further decrease in VLDL + LDL cholesterol concentration. After day 10, the VLDL + LDL cholesterol began to rise, but 


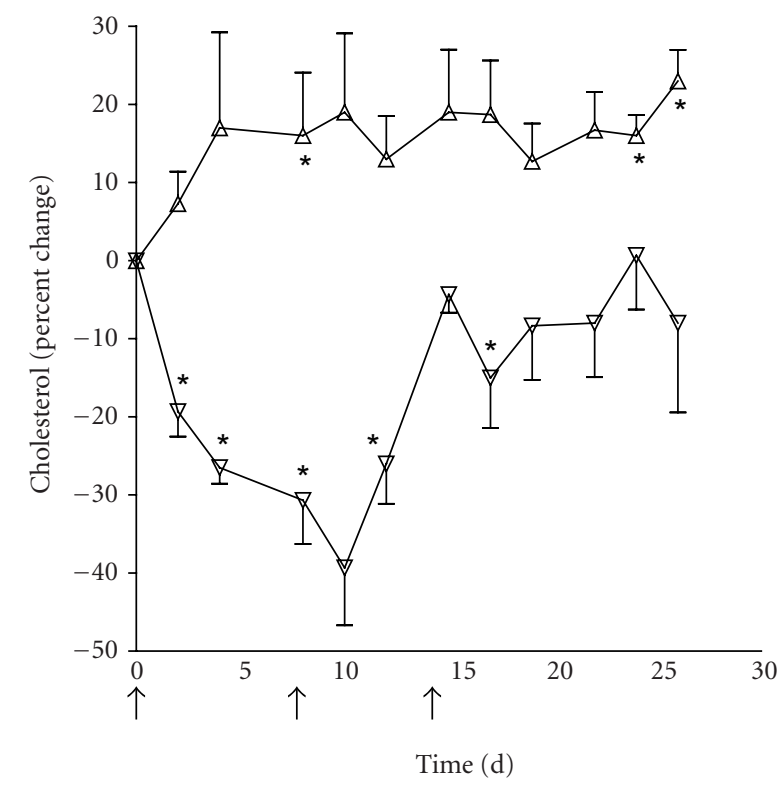

Figure 5. Average percent change in $\operatorname{HDL}(\Delta)$ and VLDL + LDL $(\nabla)$ cholesterol concentrations in baboons after intravenous injections of the truncated apoC-I peptide at 10,15 , and $20 \mathrm{mg} / \mathrm{kg}$ on days 0,7 , and 14, respectively (arrows). The baboons were fed the HCHF diet. Values are expressed as mean $\pm \mathrm{SE}, n=3$. Values significantly different from those at day 0 are marked by an asterisk $(P<.05)$.

after the third injection on day $14(20 \mathrm{mg} / \mathrm{kg})$, the VLDL + LDL cholesterol decreased further but there was very little change in the HDL cholesterol concentration. After day 20, VLDL + LDL cholesterol began decreasing till it reached baseline values by day 25 . However, as with the subcutaneous injections, the HDL cholesterol remained elevated until day 28. The maximum decrease in VLDL + LDL cholesterol concentration was $40 \%$, whereas the maximum increase in HDL cholesterol concentration was $20 \%(P<.05)$.

As presented in Figure 6, there was an increase in apoA-I in plasma after the injection of truncated apoC-I peptide. The baseline values for apo A-I were 133.67 \pm 1.45 (mean \pm SE, $n=3$ ). After the initial injection, there was a small increase in apoA-I levels; however, after the second and third injections, there was a rapid and larger increase in apoA-I in the plasma. There was a $20 \%$ increase in apoA-I after the second injection but the levels returned to baseline on day 28. Values of ApoA-I concentration after the treatment with apoC-I truncated peptide were significantly higher than the baseline values on days 10,15 , 17 , and $23(P<.05)$.

In contrast to plasma apoA-I levels, plasma apoE levels decreased in response to each injection of the peptide intravenously (Figure 6). The maximum decrease in apoE was $25 \%$ on day 10 . The baseline values for apoE were $4.37 \pm 0.62(\operatorname{mean} \pm \mathrm{SE}, n=3)$. Values of apoE concentration were significantly lower than the baseline values on days $2,8,10,19,22$, and $26(P<.05)$.

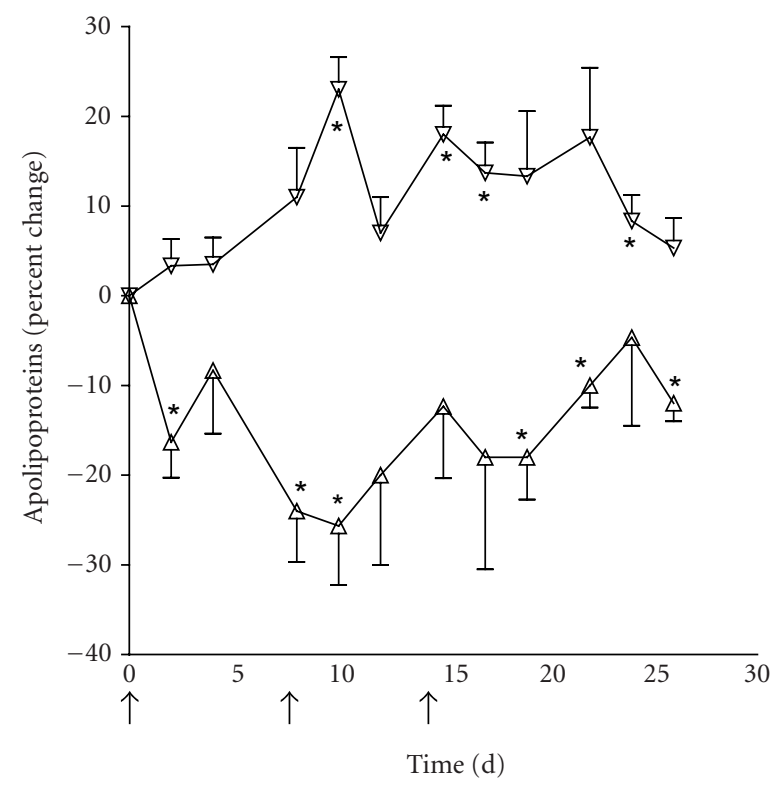

Figure 6. Average percent change in apolipoprotein A-I $(\nabla)$ and apolipoprotein $\mathrm{E}(\Delta)$ concentrations in baboons after intravenous injections of the truncated apoC-I peptide at 10 , 15 , and $20 \mathrm{mg} / \mathrm{kg}$ on days 0,7 , and 14, respectively (arrows). The baboons were fed the HCHF diet. Values are expressed as mean \pm SE, $n=3$. Values significantly different from those at day 0 are marked by an asterisk $(P<.05)$.

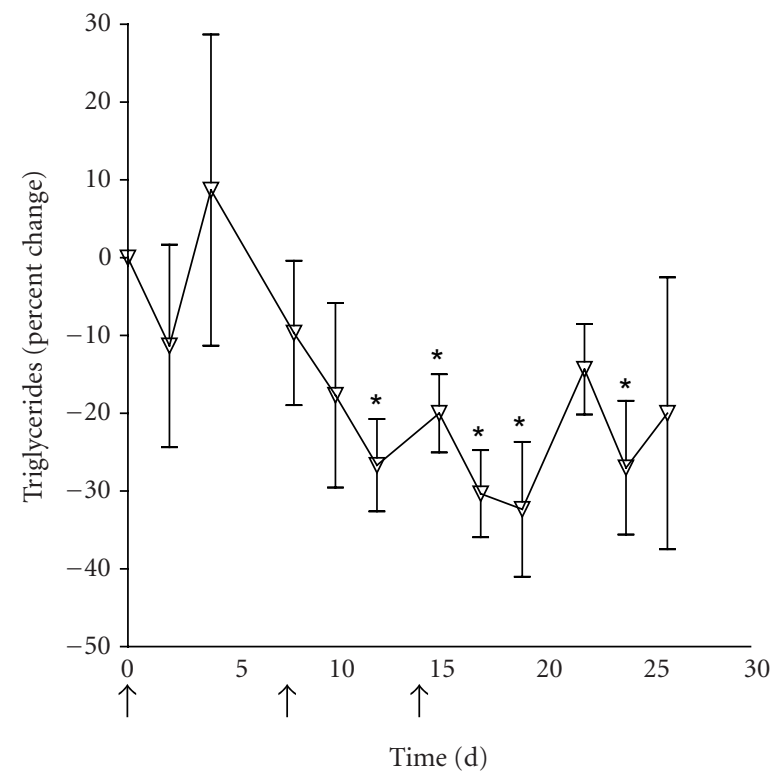

Figure 7. Average percent change in plasma triglyceride concentrations in baboons after intravenous injections of the truncated apoC-I peptide at 10,15 , and $20 \mathrm{mg} / \mathrm{kg}$ at days 0,7 , and 14 , respectively (arrows). The baboons were fed the HCHF diet. Values are expressed as mean $\pm \mathrm{SE}, n=3$. Values significantly different from those at day 0 are marked by an asterisk $(P<.05)$.

Percent change in triglycerides in baboons after the injection of truncated apoC-I peptide intravenously is shown in Figure 7. Except at day 4, plasma triglycerides 
decreased until day 19, after which they started to go up. However, even after day 26, the triglyceride concentrations were lower than at the baseline level. The values of plasma triglycerides were lower than baseline values on days $12,15,17,19$, and $23(P<.05)$.

\section{IgG levels, body weights, and food consumption}

The average values of plasma IgG levels in each baboon in response to truncated apoC-I peptide infusion did not change significantly (individual values for each baboon were $5.83 \pm 0.09,7.52 \pm 0.12$, and $6.57 \pm 0.16$, mean \pm SE, $n=12$ ). Similarly, there was no change in either the body weights or food consumption (data not shown)

\section{Half-life of the truncated apoC-I peptide in the plasma}

The radioactivity was plotted as a percent of radioactivity recovered at day 2. For calculation of the half-life of the peptide, the decay of radioactivity was plotted from day 30 to day 60. There was a log-linear decay of the peptide radioactivity. On the basis of log-linear decay, the half-life of the peptide was 14 days. The half-life of the truncated apoC-I peptide was the same in both the subcutaneous and the intravenous studies.

\section{DISCUSSION}

Our results demonstrate that the truncated apoC-I peptide (human sequence) raises HDL cholesterol in two species of nonhuman primates. The increase in HDL cholesterol was preceded by a sharp and immediate decrease in VLDL + LDL cholesterol. There was no adverse effect on the immune response, body weight, or food consumption of the baboons or cynomolgus monkeys. Thus, the peptide appears to be safe. The increase in HDL cholesterol was accompanied by a decrease in triglyceride concentration. The optimal dose of the peptide was $10 \mathrm{mg} / \mathrm{kg}$ body weight, and it had a long half-life (14 days) in circulation.

Because the truncated apoC-I peptide is very hydrophobic, we used DMSO to dissolve it. This procedure raises a question of whether any of the effects on lipid levels observed were mediated by the DMSO. We did not inject DMSO into control animals. However, we used different amounts of DMSO in subcutaneous and intravenous experiments $(0.075$ versus $1.0 \mathrm{~mL})$, but did not observe any difference in the effect of large amounts of DMSO on plasma lipid levels. Therefore, we concluded that the observed effects on lipid levels were due to the truncated apoC-I peptide.

We have established that both synthetic and natural (isolated from baboon plasma) truncated apoC-I peptides act as an inhibitor of CETP [10]. Lipoproteins isolated from animals infused with truncated apoC-I peptide have decreased cholesteryl ester transfer from HDL to VLDL + LDL in presence of CETP. As presented in Figure 1, the truncated peptide added in the plasma at $25 \mu \mathrm{M}$ substantially inhibits cholesteryl ester from HDL to VLDL + LDL. Since the transfer of cholesteryl ester from HDL to VLDL + LDL in the plasma is mediated only by the CETP, these results suggest that the truncated peptide inhibits the CETP activity in the plasma.

Statins, which are strong inhibitors of 3-hydroxy-3methyl-CoA reductase, have been used effectively to lower VLDL + LDL cholesterol and reduce the risk of CHD in high- (VLDL + LDL) subjects [15]. However, low levels of HDL cholesterol are also associated with increased risk of CHD [16]. Niacin is the only drug that has been shown to raise HDL cholesterol effectively [17], but the increase in HDL cholesterol is minimal and the drug is often not tolerated by subjects. Therefore, new drugs are needed to safely raise HDL cholesterol levels.

A deficiency of CETP is associated with increased HDL cholesterol levels and less atherosclerosis in human subjects $[18,19,20,21]$. Inhibiting CETP activity has been a potential target to raise HDL cholesterol $[22,23]$, but the CETP target has been controversial because of conflicting results from a number of studies in humans and animal models $[24,25]$. In some cases, decreased CETP was associated with increased risk of atherosclerosis. However, the majority of studies suggest that deficiency of CETP raises HDL and is antiatherogenic [26]. A recent study suggests that human subjects with a mutation in CETP (codon 405) had lower CETP activity, larger HDL and LDL particles, and the phenotype was associated with greater longevity and lower prevalence of hypertension, cardiovascular disease, and the metabolic syndrome [27].

A number of CETP inhibitors have been described. Some of these are synthetic compounds, whereas others are naturally occurring components of plasma in humans and animals $[10,28,29,30,31,32,33,34]$. These compounds inhibit CETP activity, thereby preventing cholesteryl ester from converting to apoB-containing lipoproteins, which in turn increases the LDL receptor activity [35]. A decrease in cholesteryl ester from HDL to VLDL + LDL would increase HDL cholesterol that is larger in size $[9,36]$. The results of our present studies also show that the initial action of the CETP inhibitor peptide in both species of nonhuman primates is that it leads to a rapid decrease in the VLDL + LDL cholesterol, possibly by increasing LDL receptor expression in the liver. The increase in HDL cholesterol is slower but continues even after the effect of CETP inhibitor on the VLDL + LDL cholesterol concentration has diminished.

Synthetic CETP inhibitors in animal models prevent atherosclerosis [31,37]. The present studies using truncated apoC-I peptide in nonhuman primates demonstrate the beneficial effect of the CETP inhibitor peptide on plasma lipoprotein profile. However, these studies do not show whether the peptide would prevent atherosclerosis in humans or animals. Because the peptide occurs naturally in some families of baboons, we have compared the aortic lesions in half sib pairs of baboons with or without 
the truncated apoC-I peptide [38]. Baboons having the truncated peptide had much less aortic lesions than baboons without the truncated peptide even though they had similar levels of plasma and VLDL + LDL cholesterol. These observations suggest that the presence of the naturally occurring peptide in the plasma of baboons prevents atherosclerosis. Thus, the use of truncated peptide would not only decrease VLDL + LDL and raise HDL, but would also prevent the development of atherosclerosis.

Gene therapy with several genes in animal models has prevented atherosclerosis. For example, VLDL + LDL receptor-deficient mice treated with helper-dependent adenovirus containing apoA-I gene had higher plasma HDL cholesterol and fewer arterial lesions as compared with mice treated with saline alone [39]. The HDL in mice with apoA-I gene transfer was also larger than the HDL in mice treated with saline [39]. In addition to increasing HDL, the CETP inhibitor also decreases VLDL + LDL cholesterol. Therefore, the use of apoC-I truncated peptide for gene therapy may be superior to that of apoA-I to raise HDL and prevent atherosclerosis. These characteristics of the apoC-I truncated peptide may make it an ideal inhibitor of CETP to be used for treating hypoalphalipoproteinemic humans to raise HDL levels by infusions or by gene therapy.

\section{ACKNOWLEDGMENT}

This work was supported by BioNumerik Pharmaceuticals, Inc, San Antonio, Tex.

\section{REFERENCES}

[1] Miller NE. Associations of high-density lipoprotein subclasses and apolipoproteins with ischemic heart disease and coronary atherosclerosis. Am Heart J. 1987;113(2):589-597.

[2] Pometta D, James R, Suenram A. HDL and coronary heart disease: a familial trend. Adv Exp Med Biol. 1987;210:219-224.

[3] Barter PJ, Rye KA. High density lipoproteins and coronary heart disease. Atherosclerosis. 1996;121(1): $1-12$.

[4] Heiss G, Johnson NJ, Reiland S, Davis CE, Tyroler HA. The epidemiology of plasma high-density lipoprotein cholesterol levels. The lipid research clinics program prevalence study. Summary. Circulation. 1980;62(4):IV116-IV136.

[5] Williams MC, Kushwaha RS, McGill HC, Jr.. Quantitation of baboon lipoproteins by high performance gel exclusion chromatography. Lipids. 1987;22(5): 366-374.

[6] Kushwaha RS, Rainwater DL, Williams MC, Getz GS, McGill HC, Jr,. Impaired plasma cholesteryl ester transfer with accumulation of larger high density lipoproteins in some families of baboons (Papio sp.). J Lipid Res. 1990;31(6):965-973.
[7] Breslow JL, Eisenberg S, Brinton EA. Metabolic determinants of low HDL-C levels. Ann N Y Acad Sci. 1993;676:157-162.

[8] Gartside PS, Khoury P, Glueck CJ. Determinants of high-density lipoprotein cholesterol in blacks and whites: the second national health and nutrition examination survey. Am Heart J. 1984;108(3): 641653.

[9] Pape ME, Rehberg EF, Marotti KR, Melchior GW. Molecular cloning, sequence, and expression of cynomolgus monkey cholesteryl ester transfer protein. Inverse correlation between hepatic cholesteryl ester transfer protein mRNA levels and plasma high density lipoprotein levels. Arterioscler Thromb. 1991;11(6):1759-1771.

[10] Kushwaha RS, Hasan SQ, McGill HC, Jr, Getz GS, Dunham RG, Kanda P. Characterization of cholesteryl ester transfer protein inhibitor from plasma of baboons (Papio sp.). J Lipid Res. 1993;34 (8):1285-1297.

[11] Bagdade JD, Koerker DJ, Ritter MC, Weigle DS, Goodner CJ. Accelerated cholesteryl ester transfer in baboons with insulin-requiring diabetes mellitus. Horm Metab Res. 1995;27 (2):70-75.

[12] Lauer SJ, Walker D, Elshourbagy NA, Reardon CA, Levy-Wilson B, Taylor JM. Two copies of the human apolipoprotein C-I gene are linked closely to the apolipoprotein E gene. J Biol Chem. 1988;263 (15):7277-7286.

[13] McGill HC, Jr, McMahan CA, Kushwaha RS, Mott GE, Carey KD. Dietary effects on serum lipoproteins of dyslipoproteinemic baboons with high HDL1. Arteriosclerosis. 1986;6(6):651-663.

[14] Mott GE, McMahan CA, Kelley JL, Farley CM, McGill HC, Jr.. Influence of infant and juvenile diets on serum cholesterol, lipoprotein cholesterol, and apolipoprotein concentrations in juvenile baboons (Papio sp.). Atherosclerosis. 1982;45(2):191-202.

[15] Aronow WS. Hypercholesterolemia. The evidence supports use of statins. Geriatrics. 2003;58(8):18-20, 26-28, 31-32.

[16] Pirro M, Siepi D, Lupattelli G, et al. Plasma Creactive protein in subjects with hypo/hyperalphalipoproteinemias. Metabolism. 2003;52(4):432-436.

[17] Malik S, Kashyap ML. Niacin, lipids, and heart disease. Curr Cardiol Rep. 2003;5(6):470-476.

[18] Kakko S, Tamminen M, Paivansalo M, et al. Variation at the cholesteryl ester transfer protein gene in relation to plasma high density lipoproteins cholesterol levels and carotid intima-media thickness. Eur J Clin Invest. 2001;31(7):593-602.

[19] Kimura H, Miyazaki R, Suzuki S, Gejyo F, Yoshida H. Cholesteryl ester transfer protein as a protective factor against vascular disease in hemodialysis patients. Am J Kidney Dis. 2001;38(1):70-76.

[20] Gudnason V, Kakko S, Nicaud V, et al. Cholesteryl ester transfer protein gene effect on CETP activity and plasma high-density lipoprotein in European 
populations. The EARS group. Eur J Clin Invest. 1999;29(2):116-128.

[21] Nishiwaki M, Ishikawa T, Ito T, et al. A remarkable increase in high-density lipoprotein-cholesterol by alcohol intake in a homozygous patient with cholesteryl ester transfer protein deficiency. Ann $N$ Y Acad Sci. 1995;748:626-629.

[22] Barter PJ, Brewer HB, Jr, Chapman MJ, Hennekens $\mathrm{CH}$, Rader DJ, Tall AR. Cholesteryl ester transfer protein: a novel target for raising HDL and inhibiting atherosclerosis. Arterioscler Thromb Vasc Biol. 2003;23(2):160-167.

[23] Kawashiri MA, Maugeais C, Rader DJ. High-density lipoprotein metabolism: molecular targets for new therapies for atherosclerosis. Curr Atheroscler Rep. 2000;2(5):363-372.

[24] Zhong S, Sharp DS, Grove JS, et al. Increased coronary heart disease in Japanese-American men with mutation in the cholesteryl ester transfer protein gene despite increased HDL levels. J Clin Invest. 1996;97(12):2917-2923.

[25] Hayek T, Masucci-Magoulas L, Jiang X, et al. Decreased early atherosclerotic lesions in hypertriglyceridemic mice expressing cholesteryl ester transfer protein transgene. J Clin Invest. 1995;96(4):20712074.

[26] Hirano K, Yamashita S, Matsuzawa Y. Pros and cons of inhibiting cholesteryl ester transfer protein. Curr Opin Lipidol. 2000;11(6):589-596.

[27] Barzilai N, Atzmon G, Schechter C, et al. Unique lipoprotein phenotype and genotype associated with exceptional longevity. JAMA. 2003;290(15):20302040.

[28] Nishide T, Tollefson JH, Albers JJ. Inhibition of lipid transfer by a unique high density lipoprotein subclass containing an inhibitor protein. J Lipid Res. 1989;30(2):149-158.

[29] Morton RE. Cholesteryl ester transfer protein and its plasma regulator: lipid transfer inhibitor protein. Curr Opin Lipidol. 1999;10(4):321-327.

[30] Sikorski JA, Connolly DT. The discovery of new cholesteryl ester transfer protein inhibitors. Curr Opin Drug Discov Devel. 2001;4(5):602-613.

[31] Okamoto H, Yonemori F, Wakitani K, Minowa T, Maeda K, Shinkai H. A cholesteryl ester transfer protein inhibitor attenuates atherosclerosis in rabbits. Nature. 2000;406(6792):203-207.

[32] Reinhard EJ, Wang JL, Durley RC, et al. Discovery of a simple picomolar inhibitor of cholesteryl ester transfer protein. J Med Chem. 2003;46(11):21522168.

[33] Bonin PD, Bannow CA, Smith CW, Fischer HD, Erickson LA. A peptide inhibitor of cholesteryl ester transfer protein identified by screening a bacteriophage display library. J Pept Res. 1998;51(3):216225.

[34] Gautier T, Masson D, de Barros JP, et al. Human apolipoprotein C-I accounts for the ability of plasma high density lipoproteins to inhibit the cholesteryl ester transfer protein activity. J Biol Chem. 2000;275(48):37504-37509.

[35] Sugano M, Makino N, Sawada S, et al. Effect of antisense oligonucleotides against cholesteryl ester transfer protein on the development of atherosclerosis in cholesterol-fed rabbits. J Biol Chem. 1998;273 (9):5033-5036.

[36] Koizumi J, Mabuchi H, Yoshimura A, et al. Deficiency of serum cholesteryl-ester transfer activity in patients with familial hyperalphalipoproteinaemia. Atherosclerosis. 1985;58(1-3):175-186.

[37] MacLean PS, Bower JF, Vadlamudi S, et al. Cholesteryl ester transfer protein expression prevents diet-induced atherosclerotic lesions in male db/db mice. Arterioscler Thromb Vasc Biol. 2003;23 (8):1412-1415.

[38] Kushwaha RS, McGill HC, Jr,. Diet, plasma lipoproteins and experimental atherosclerosis in baboons (Papio sp.). Hum Reprod Update. 1998;4(4):420-429.

[39] Belalcazar LM, Merched A, Carr B, et al. Longterm stable expression of human apolipoprotein A-I mediated by helper-dependent adenovirus gene transfer inhibits atherosclerosis progression and remodels atherosclerotic plaques in a mouse model of familial hypercholesterolemia. Circulation. 2003;107(21):2726-2732.

* Corresponding author.

E-mail: kush@icarus.sfbr.org

Fax: +1 210670 3323; Tel: +1 2102589615 

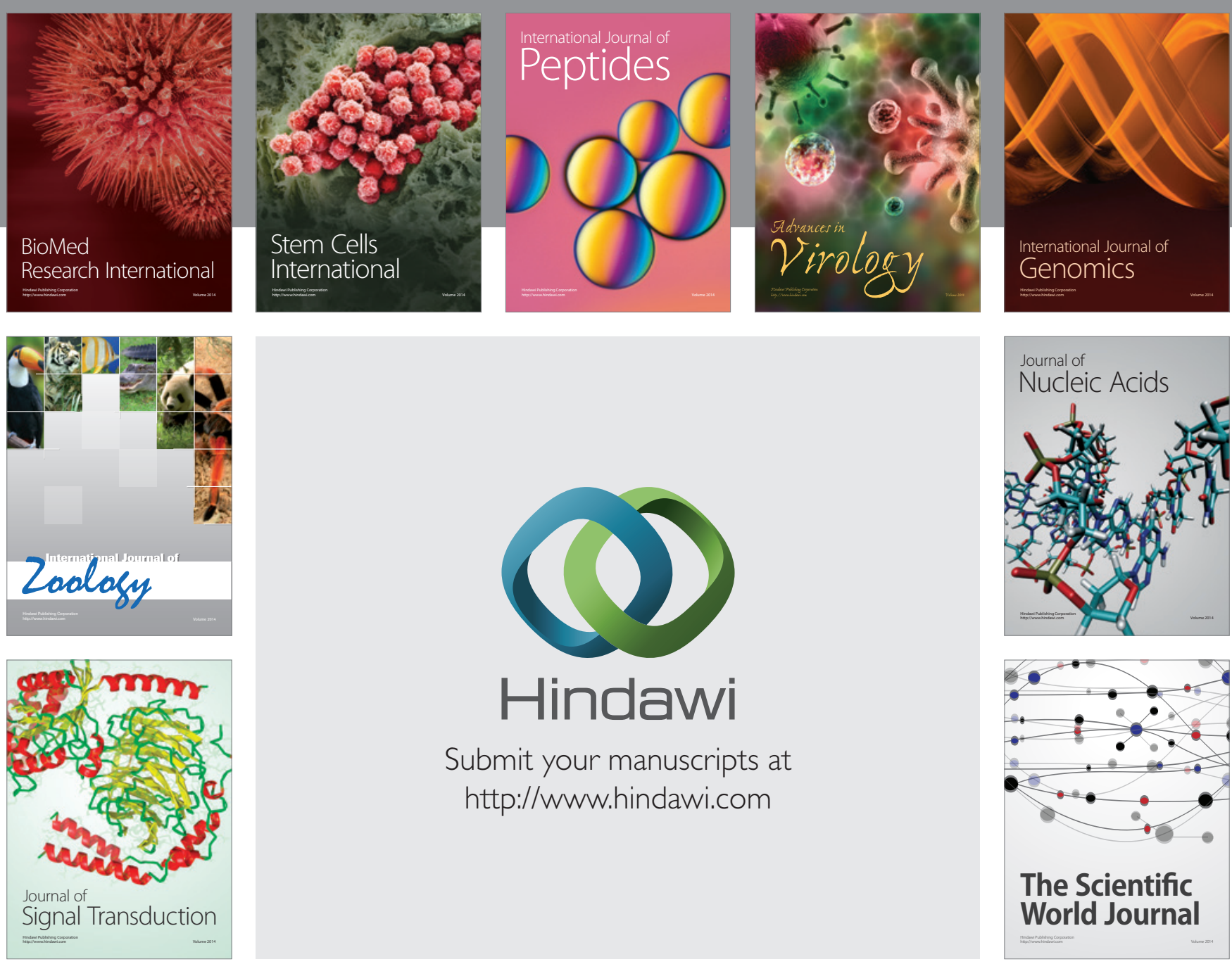

Submit your manuscripts at

http://www.hindawi.com
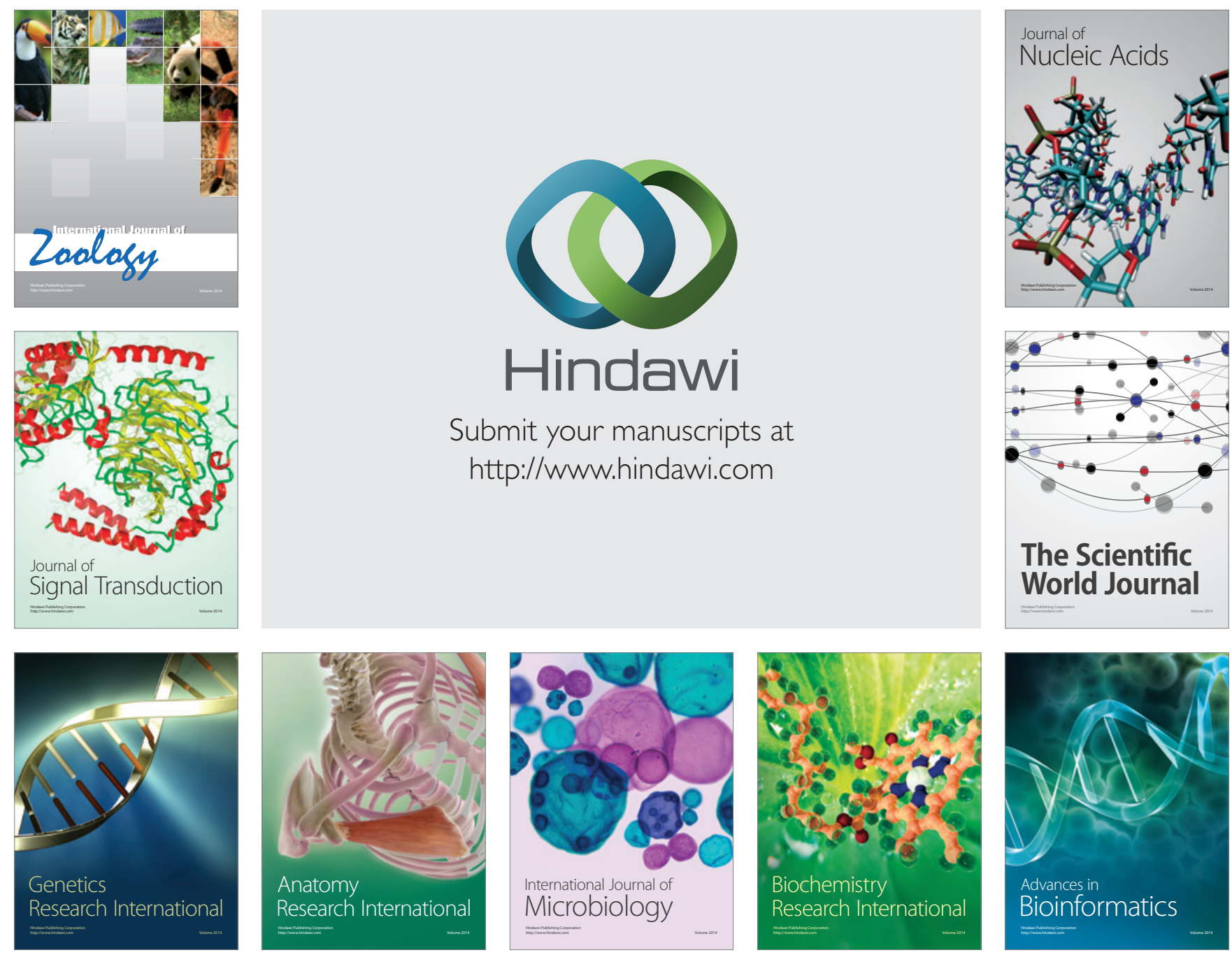

The Scientific World Journal
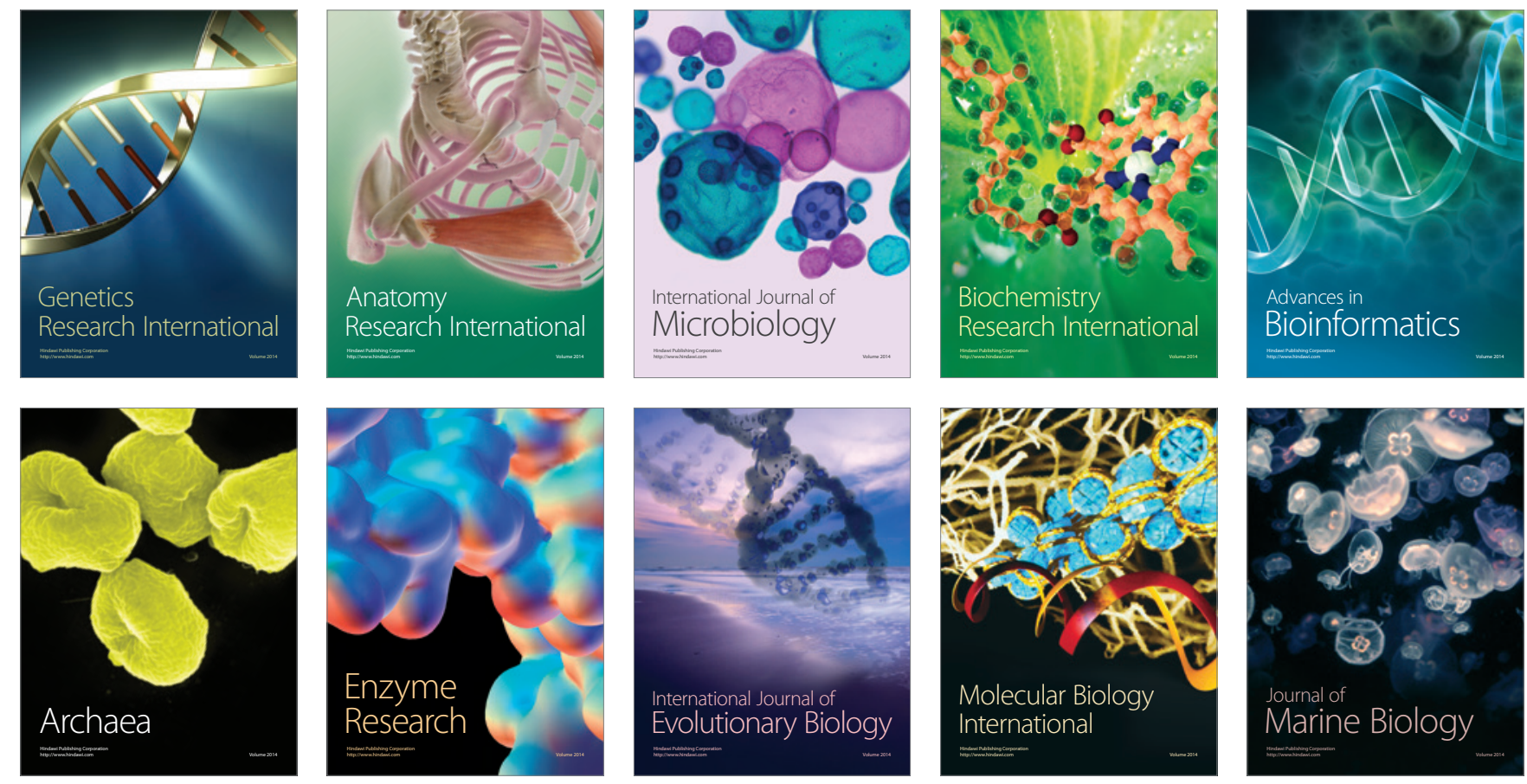